\title{
Use of chemotherapy to treat hepatocellular carcinoma
}

\author{
Ziqi Hou ${ }^{1,}$, Jie Liu ${ }^{2, \S}$, Zhaoxing Jin ${ }^{1}$, Guoteng Qiu ${ }^{1}$, Qingyun Xie ${ }^{1}$, Shizheng Mi ${ }^{1}$, \\ Jiwei Huang ${ }^{1, *}$
}

${ }^{1}$ Department of Liver Surgery and Liver Transplantation Center, West China Hospital, Sichuan University, Chengdu, China;

${ }^{2}$ Orthopedics, Tianjin Medical University General Hospital, Tianjin, China.

SUMMARY Hepatic malignancies remain a global challenge. Hepatocellular carcinoma (HCC) accounts for around $90 \%$ of patients with liver cancer and is the sixth most common neoplasm worldwide and the fourth leading cause of cancer-related death. However, the long-term prognosis for HCC remains far from satisfactory, with a late diagnosis and limited treatment. DOX has served as conventional chemotherapy with the longest history of use. Although conventional chemotherapy is being challenged by molecular therapy and immune therapy, there is renewed optimism and interest in both systematic and locoregional therapy. Combined chemotherapy is widely used in clinical practice. In specific terms, FOLFOX can serve as a first-line (category 2B) option as recommended by the 2021 NCCN guidelines, while the efficacy of LTLD plus RFA has been confirmed in the phase III HEAT study. These approaches have challenged the dominant status of molecular therapy in terms of health economics and they have potential benefits in Asia, where HBV-related hepatocellular carcinoma is prevalent. Moreover, locoregional chemotherapy can be achieved with TACE and HAIC (possibly involving FOLFOX, DOX, mitomycin C, cisplatin, epirubicin, etc.). TACE was officially recommended by the 2021 NCCN guidelines for patients with Child-Pugh class B liver disease. In addition, HAIC has demonstrated a potential advantage in preliminary clinical practice, although it hasn't been included in any guidelines. Hence, this review summarizes largescale trials and studies examining the development and innovative use of chemotherapeutic agents. Mounting clinical evidence warrants an exploration of the efficacy of chemotherapy.

Keywords chemotherapy, hepatocellular carcinoma, immune therapy, molecular therapy

\section{Introduction}

Primary hepatic malignancies include hepatocellular carcinoma (HCC) and intrahepatic cholangiocarcinoma originating from the parenchyma. In addition, rare primary lesions originating from the mesenchyme develop into liver sarcoma. HCC is the sixth most common neoplasm worldwide and the fourth leading cause of cancer-related death, and it accounts for around $90 \%$ of patients with hepatic malignancies with an unfavorable prognosis due to its largely asymptomatic natural history (1), high recurrence, and ineffective therapeutic strategies for advanced HCC (2-5) (Figure 1). Hepatitis B virus (HBV) infection is an independent high risk factor for HCC among unvaccinated persons, mostly in Asia and sub-Saran Africa (6). In addition, hepatitis C virus $(\mathrm{HCV})$ infection, dietary exposure to aflatoxin $\mathrm{B} 1$, and alcoholic liver disease (ALD) and nonalcoholic fatty liver disease (NAFLD) have become the leading causes of HCC in developed countries $(7,8)$.
Currently, there are various controversies regarding the therapeutic options for HCC. Since localized liver cancer is asymptomatic for much of its natural history, the major obstacles are a late diagnosis and a subsequently low resection rate, limiting treatment alternatives. Thus, a significant fraction of patients will eventually become eligible for chemotherapy. Chemotherapy has become a conventional option for HCC as a result of drug research and development. These drugs play an indispensable role in systematic therapy and are also being developed to act on locoregional targets through approaches such as transarterial chemoembolization (TACE) and hepatic artery infusion chemotherapy (HAIC). Here, chemotherapy is outlined and its corresponding role in treating HCC has been described.

The stage of $\mathrm{HCC}$ is identified using various staging systems, namely Barcelona Clinic Liver Cancer (BCLC) tumor staging, the Hong Kong Liver Cancer staging system (3,9), and the Cancer of the Liver Italian Program (10). The BCLC is most widely used and was introduced 


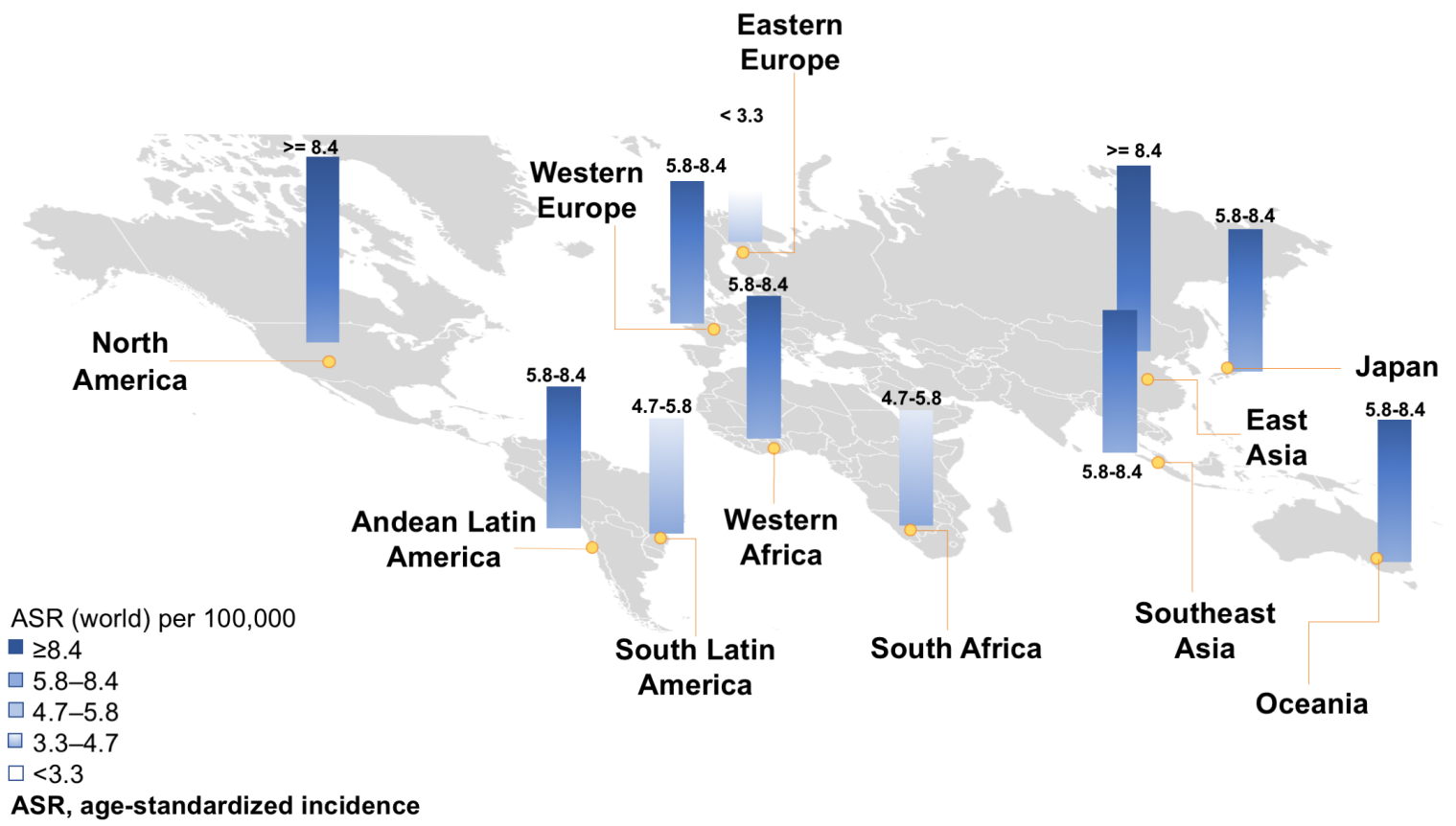

Figure 1. The incidence of HCC by geographical area. HCC is a worldwide problem and it is concentrated in East Asia and North America, as reflected by the age-standardized incidence.

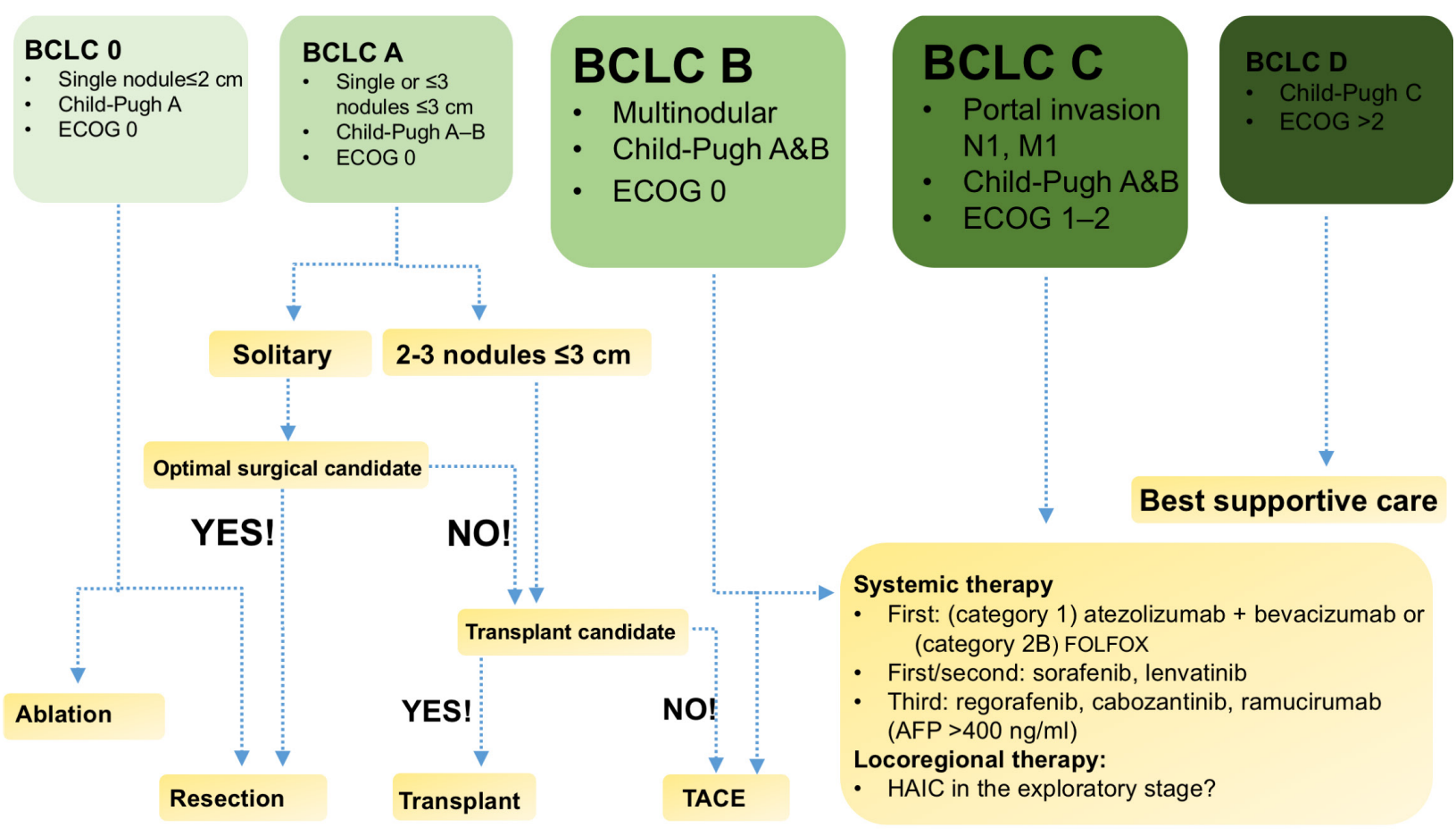

Figure 2. Clinical algorithm for the management of HCC. This algorithm, based on the Barcelona Clinic Liver Cancer algorithm, classifies patients into one of five stages, corresponding to graded therapies recommend by the $2021 \mathrm{NCCN}$ guidelines.

in $1999(3,11)$. Since it provides a comprehensive evaluation based on liver function, performance status, and tumor burden, the BCLC system has been approved by the European Association for the Study of the Liver (4,10-12). The algorithm classifies patients into one of five stages and it provides treatment recommendations for each stage (3). (Figure 2) Based on this classification system, the use of chemotherapeutic agents for different stages of HCC has been described here (Figure 3).

\section{Systemic chemotherapy}

Systemic therapies are, along with transarterial therapies, recommended for patients with BCLC stage B or C HCC 


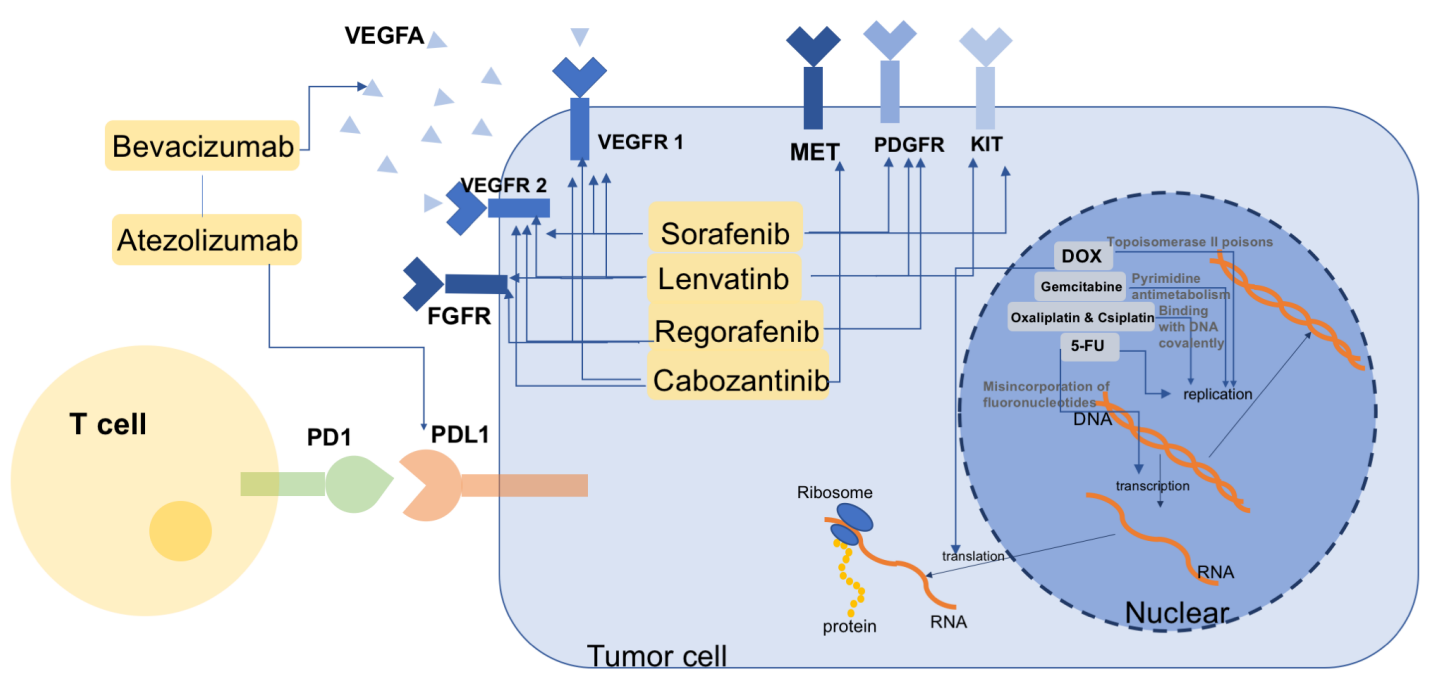

Figure 3. Mechanism of action of chemotherapy, molecular therapy, and immune therapy. The mechanism of action of chemotherapeutic agents: DOX inhibits the replication and translation of DNA via various approaches including as topoisomerase II poisons. Gemcitabine specifically kills cells in the process of DNA synthesis by disrupting pyrimidine metabolism. Platinum covalently binds directly with DNA. 5-FU induces the misincorporation of fluoronucleotides by replacing dUMP to form a ternary complex with a higher binding affinity and greater stabilization. The mechanism of molecularly targeted agents: They suppress multi-kinase, which is the key substance that activates tyrosine kinases such as VEGFRs, PDGFR, MET, and KIT. These tyrosine kinases play a key role in cell proliferation and angiogenesis in the tumor microenvironment (TME). The mechanism of immune therapy: Atezolizumab is targeted PDL1 expressed in HCC tumor cells that inhibits PD1 expressed by effector lymphocytes. Bevacizumab (a VEGF inhibitor) synergistically enhances the effectiveness of PD1 inhibition.

with progression (3). In some developing countries, $50-70 \%$ of patients are initially diagnosed with BCLC Stage C HCC because of limited systematic screening. Liver transplantation is currently with the most effective treatment, it is available for only select patients with early-stage HCC. In addition, surgical resection and ablative techniques have demonstrated advantages in terms of long-term survival, but less than $25 \%$ of patients are fortunate enough to have access to these treatments even in the West $(13,14)$. Despite the widespread use of TACE in patients with unresectable tumor lesions, systemic therapy with doxorubicin has been the standard for many years (15).

\subsection{Doxorubicin (DOX)}

DOX was used as a first-line chemotherapeutic drug for many years until the appearance of sorafenib in 2008 (13), albeit without evidence of a significant survival benefit (16). It was first introduced in the early 1960s (17) and was widely used to treat solid tumors. A bold attempt has been made to use DOX to treat HCC. Nonetheless, controversies surrounding DOX's mechanism of action abound. In a nutshell, DOX inhibits the replication and translation of DNA in various way including as a topoisomerase II poison (17) and targeting p53 (17). Like other antitumor agents, DOX was soon approved, but its drawbacks have been serious cardiac adverse events, namely chronic cardiomyopathy and congestive heart failure (CHF), and progressive drug resistance after completion therapy within a year (18). These faults have limited the maximum recommended volume of DOX to 40 to $75 \mathrm{mg} / \mathrm{m}^{2}$ according to successive clinical studies conducted from 1977 to 2007 (16). (Table 1) As a monotherapy for HCC, DOX only conferred a survival benefit of 3.0 to 4.1 months and an ORR of 19\% $(16,19)$. As diagnosis and technology have advanced, fortunate patients are more likely to receive systemic treatment in earlier stages (16), but DOX's marginal survival benefit has not changed.

\subsection{DOX derivatives}

After DOX was introduced, DOX derivatives were examined as chemotherapeutic agents. Pegylated liposomal doxorubicin (PLD) has long-acting pegylated 'stealth' liposomes encapsuling a doxorubicin hydrochloride inner core for intravenous administration to target HCC lesions. PLD has a better permeability and liposolubility that delay its clearance from the circulation via leaky capillaries, resulting in an attenuated circulation time and a superior cardiac safety profile (20). However, a phase II study found that PLD has almost no effect in advanced HCC $(20,21)$, with a response rate of $10-17 \%$ at best $(20,22)$.

When liposomal doxorubicin (LD) is pegylated, it does not have significant systemic efficacy, but lysothermosensitive LD (LTLD) locally releases a high concentration of doxorubicin and quickly diffuses into local tissues when heated to $\geq 40^{\circ} \mathrm{C}(23,24)$. The tumor concentration of doxorubicin increases 25 -fold (23). Tumor microvasculature is more permeable than normal 


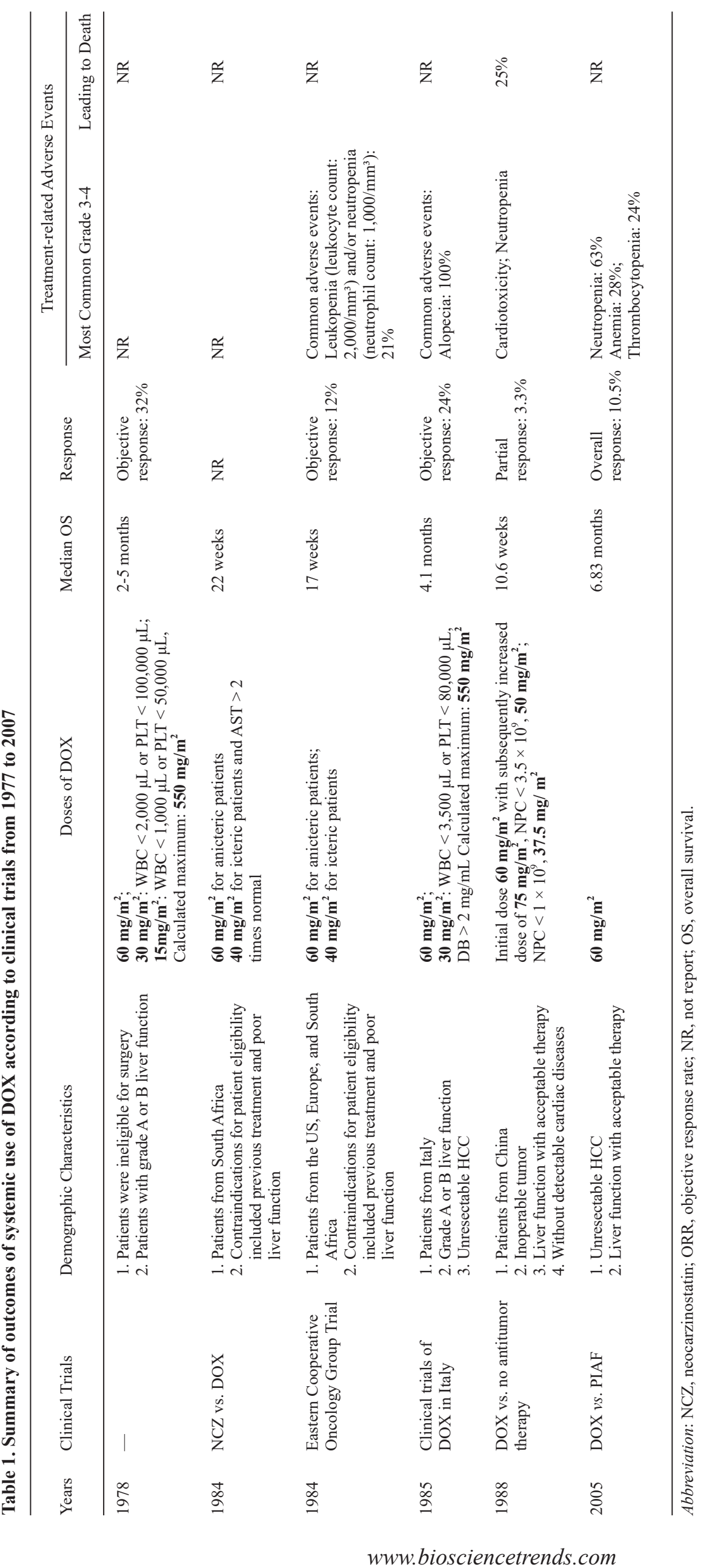


blood vessels, so LTLD is better able to reach tumors and reduce systemic toxicity (24-26). Given the significant correlation between LTLD and heat, the best approach might be to increase the local temperature using radiofrequency ablation (RFA). Recent studies involving a combination of intravenous administration of LD and RFA suggested that RF-induced thermal energy at $42^{\circ} \mathrm{C}$ in particular might yield better efficacy, improving the release of DOX from the long-circulating drug/liposome complex and resulted in accumulation of a higher concentration at the target lesion (27). In the recent phase III HEAT study, the initial complete response of multinodular intermediate-sized lesions (3-7 cm) to RFA + LTLD was $>94 \%$ and the therapeutic failure was $<$ $5 \%$ (23) according to a sub-analysis of relatively large tumors $(5-7 \mathrm{~cm})$, and median PFS was 13.9 months and the median OS was 53 months $(23,24)$. That said, there were no statistically significant differences between the RFA + LTLD arm and the RFA alone arm. However, a subsequent post hoc study suggested that prolonging the RF ablation of larger tumors would be more likely to increase efficacy and have a survival benefit (28).

\subsection{Other cytotoxic agents}

Nevertheless, DOX continues to be used as conventional chemotherapy. Continued innovation in chemotherapeutic agents is expected to result in the replacement of DOX, but studies have yielded conflicting results. For instance, fluoropyrimidine 5-fluo-rouracil (5-FU) has been widely used in a vast number of regimens and it has been used as an essential component of transarterial treatment as well (29-31). Like DOX, 5-FU suppresses DNA and RNA synthesis via the misincorporation of fluoronucleotides, and it inhibits the nucleotide-synthesizing enzyme thymidylate synthase (TS) as well. Tegafur-uracil is an oral prodrug metabolized to 5-FU mostly in the liver, and it has higher efficacy and is better tolerated (32). Nolatrexed (NOL) is a novel anticancer agent that also inhibits TS. NOL is taken up into cells without active transport, and it acts without polyglutamation (16). However, a large-scale randomized controlled trial (RCT) has compared the efficacy of DOX and NOL and found that NOL resulted in a negligible improvement in survival, with an OS of 20.7 weeks, compared to DOX (16). Thus, numerous novel cytotoxic agents have been examined, including gemcitabine, capecitabine, and oxaliplatin (33). These agents have demonstrated modest efficacy alone but considerable efficacy when used in combination (Table 2) $(29,34)$. For instance, gemcitabine kills cells in the progress of DNA synthesis by inhibiting pyrimidine metabolism, so it is specific to certain cell phases. Moreover, it is attractive as a component of a combined strategies due to its favorable nonhematologic toxicity spectrum and mild and reversible hematological toxicity profile $(35,36)$. Like gemcitabine, capecitabine targets fluoropyrimidine but via an oral protocol (37).
Capecitabine resulted in an ORR of $11 \%$, (including complete remission in 1 patient), and a disease control rate of $22 \%(29,38)$. The antitumor role of platinum was subsequently discovered by accident, and platinum-based drugs were approved in 1978. Platinum's mechanism of action, as confirmed by a number of highly reliable studies, differs from the mechanisms mentioned thus far since it interferes with DNA synthesis by covalently binding directly with DNA $(39,40)$. Typical platinumbased chemotherapeutic agents include cisplatin, carboplatin, and oxaliplatin. Cisplatin was initially found to play a significant role in treating reproductive system tumors, namely testicular and ovarian cancers, with notable toxicity to the kidneys and gastrointestinal tract (39). Cisplatin resulted in a response rate of $16-27 \%$ when used in combination to treat advanced $\operatorname{HCC}(29,31)$, but it did provide a marginal survival benefit when used alone. Cisplatin is also used in intra-arterial strategies. Indeed, cisplatin has a marginal survival benefit because its interference with DNA binding and repair diminishes as HCC becomes resistant to the drug. Carboplatin, a second-generation platinum-based drug, has greatly reduced nephrotoxicity but it has an efficacy similar to that of cisplatin. Oxaliplatin (1R,2R-diaminocyclohexane oxalatoplatinum (II)) is actively antagonistic to tumors with acquired resistance to cisplatin $(39,41,42)$, and it even overturned the previously accepted view that platinum-based drugs are insensitive to colorectal cancer (39). Interferons (IFNs) are a group of signaling cytokines secreted by immune cells. They display antitumor action by provoking antitumor immune responses and regulating the expression of proliferationrelated genes (43).

\subsection{Combination chemotherapy}

Since single agents had limited efficacy against HCC, the question is whether those drugs would be efficacious when used in combination. A phase II study indicated that a gemcitabine plus PLD regimen resulted in a response rate of $24 \%$ and it increased opportunities for surgery, including resection and transplantation, for eligible patients with unresectable HCC $(21,35,44,45)$. Due to its different mechanisms of action, it resulted in an acceptable toxicity and it prevented cross-resistance (35). In specific terms, gemcitabine promotes topoisomerase II expression, which is a process that PLD targets $(35,46)$. Thus, better results are achieved when gemcitabine is administered before PLD. In addition, a gemcitabine plus oxaliplatin (GEMOX) regimen is likely to be welltolerated when treating primary NAFLD according to a phase II study (47). The regimen results in an ORR of $18 \%$ and a disease control rate of $76 \%$. Although these figures seem to indicate a marginal benefit, the regiment resulted in durable stabilization of HCC characterized by chemo-resistance (47). Combination chemotherapy with PIAF (cisplatin, interferon, doxorubicin, and 


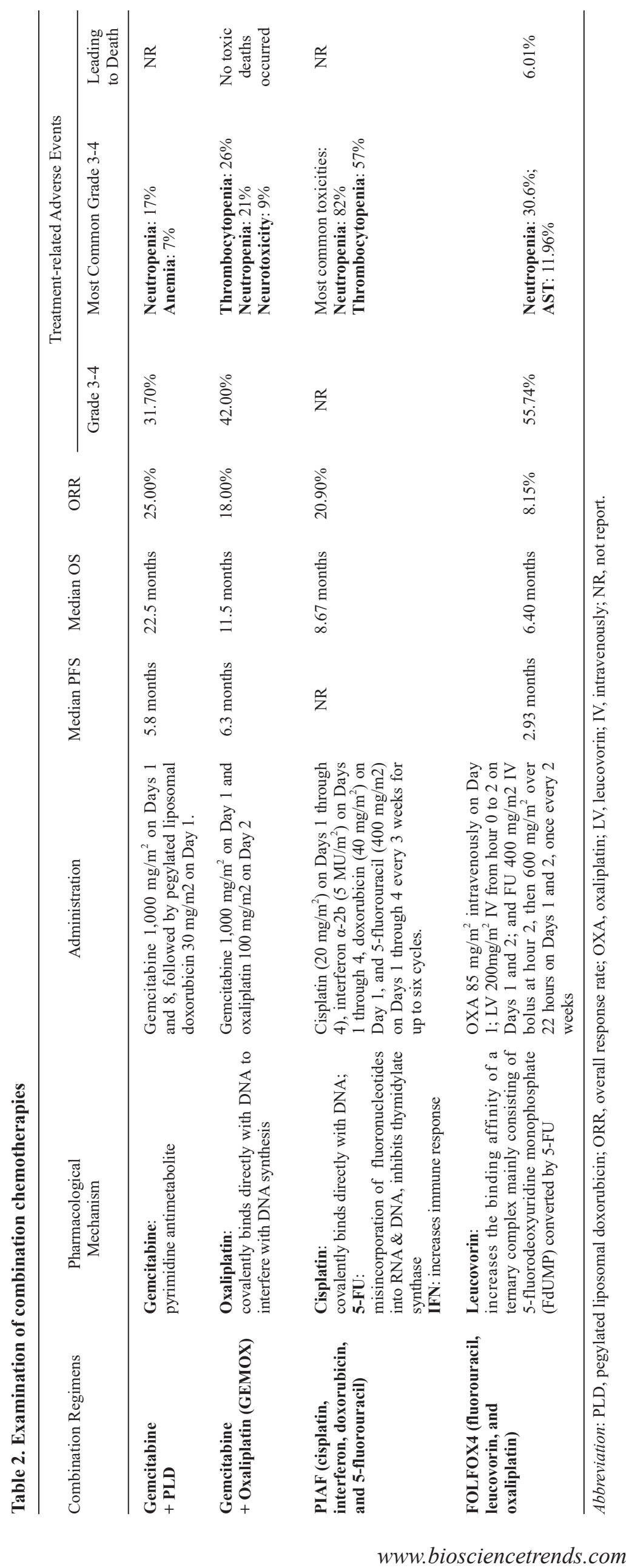


5-fluorouracil) has yielded positive outcomes in terms of a pathologic complete response (15) in a small but marked proportion of patients, and it resulted in a marginally prolonged median survival of 8.67 months (range $=6.36$ to 12.00$)$ versus DOX (6.83 months (range $=4.80$ to 9.56$)$ ) (31). Attention has continued to focus one combination chemotherapy. The drug 5-FU induces misincorporation of fluoronucleotides by replacing dUMP to form a ternary complex with a higher binding affinity and increased stabilization. The presence of leucovorin can boost ternary complex formation, and oxaliplatin can further increase efficacy. Combination chemotherapy with the FOLFOX (fluorouracil, leucovorin, and oxaliplatin) regimen has been widely used in metastatic colorectal cancer (mCRC) with demonstrable efficacy (48), and it has also been examined in advanced HCC. Although FOLFOX4 conferred a slim advantage as indicated by a median PFS of 2.93 months (2.43 to 3.53) versus DOX (1.63 to $2.30 ; P<0.001)$, it was not effective at prolonging OS (6.4 months versus 4.97 months, $P>0.05$ ) according to a phase III study (49). That said, FOLFOX4 offered a statistically significant benefit in terms of OS when used to treat metastatic HCC (49). Given its limited superiority in terms of a statistically significant survival benefit, the 2021 clinical practice guidelines of the NCCN recommend that FOLFOX serve as a first-line (category 2B) option (1).

Numerous studies have examined chemotherapy with various combinations of drugs, such as capecitabine plus cisplatin (XP) (29) and gemcitabine plus carboplatin (50). Nevertheless, these trials noted only a modest and inconsistent efficacy.

In summary, HCC is a multidrug-resistant tumor caused by a high level of MDR1 expression (51). Randomized trials of novel therapeutics have failed to note a significantly improved survival until recently, with a median OS of 6 to 8 months (35). Systematic chemotherapy is modestly effective in treating HCC (49).

\subsection{Chemotherapy and molecular therapy}

Examination of subsequent approaches to treating advanced HCC has ushered in a new era of molecularly targeted agents (MTAs) (Table 3) and immune therapy (52). Sorafenib was the first systemic molecular agent approved by the FDA, and it is rapidly replacing DOX as the drug of choice for frontline therapy (3). Sorafenib targets multi-kinases, including the serine-threonine kinases Raf-1 and B-Raf, and tyrosine kinases, which are key substances that activate vascular endothelial growth factor receptors (VEGFRs) and platelet-derived growth factor receptors (PDGFR- $\beta$ ). These receptors play a key role in cell proliferation and angiogenesis in the tumor microenvironment (TME) (53-55). The SHARP trial (a phase III RCT) initially noted an improved prognosis in cases of advanced HCC, with a median survival benefit of nearly 3 months and a median OS of 10.7 months versus the placebo group $(52,53)$. The National Institute for Health and Clinical Excellence argued that sorafenib had limited cost-effectiveness as a first-line treatment for advanced HCC (35). Therefore, studies examined MTAs, including erlotinib (56), brivanib (57), sunitinib (58), linifanib (59), and everolimus (60), as a way to achieve greater efficacy at a lower cost. However, a global phase III trial found that these agents had efficacy no better than or on par with what of sorafenib (3). Studies on MTAs appeared to have reached an impasse, but lenvatinib subsequently appeared as an alternative for advanced HCC with a broader pharmacological mechanism profile against VEGFR, FGFR, PDGFR $\alpha$, RET, and KIT (61). According to a phase III trial, lenvatinib resulted in an OS of 13.6 months (95\% CI 12.1-14.9 months) similar to that of sorafenib (12.3 months, 95\%CI 0.79-1.06 months) (61). However, all secondary efficacy endpoints were statistically superior, namely PFS, TTP, and OR (61). Moreover, a recent cost-utility analysis found that lenvatinib was superior in cost (62). Lenvatinib is reasonably given priority (62). Recently, the 2021 clinical practice guidelines of the NCCN recommended sorafenib and lenvatinib as a category 1 option for patients with Child-Pugh class A liver function (1). In addition, the later phase III RESORCE trial (63) and CELESTIAL trial confirmed the role of regorafenib and cabozantinib, both of which are oral multikinase inhibitors, as subsequent-line therapy in the event of disease progression after sorafenib administration (1).

Although clinical trials have demonstrated the benefits of sorafenib and lenvatinib, a retrospective study in South Korea reached the opposite view. In that study, the efficacy of conventional chemotherapy (fluorouracil plus doxorubicin and platinum) was not inferior to that of sorafenib (34); this finding is presumably due to the fact that trials included patients with Child-Pugh class B or C liver disease. Moreover, sorafenib alone had a limited benefit in select patients with extrahepatic disease (49). In addition, a pivotal phase III study in Asia demonstrated that sorafenib has modest efficacy, with an OS of 6.5 months (95\% CI 5.56-7.56 months) versus 4.2 months in the placebo arm (95\% CI, 3.75-5.46 months). Although the HRs were comparable between that study and the SHARP trial, the OS in Asia was inferior to that in the West (64). This is presumably due to the higher proportion of patients infected with $\mathrm{HBV}$ or poor screening in developing countries $(64,65)$. A subsequent systemic review confirmed that sorafenib had superior efficacy in cases of non-metastatic HCC caused by HCV (5). The rapid emergence of sorafenib resistance in the majority of patients and the conflict between high costs and low incomes has limited its use in Asia (34). Use of MTAs and alternative chemotherapies is hotly contested in abound in certain countries.

Would the combination of sorafenib and chemotherapeutic agents result in a considerable 


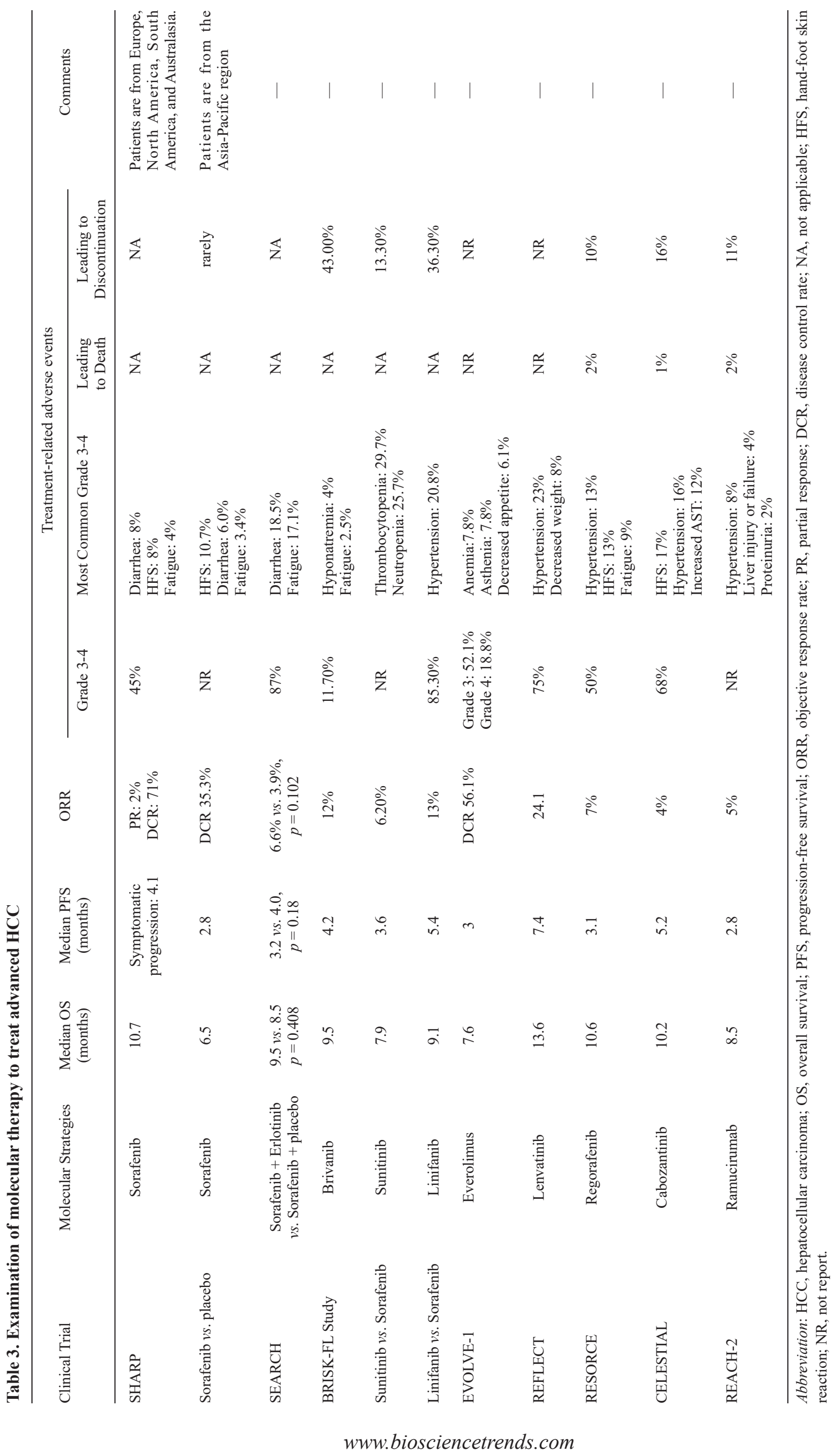


survival benefit? Sorafenib plus DOX (34), sorafenib plus GEMOX $(66,67)$, sorafenib plus tegafur-uracil (UFT)(32), and other combinations have been studied in clinical trials, but they all demonstrated a moderate benefit in terms of PFS versus sorafenib alone.

\subsection{Chemotherapy and immune therapy}

Immune therapy's mechanism of action is based on the TME around the malignant lesion and dysfunctional tumor-immune system interactions, which lead to immune evasion by reducing the recognition of tumorassociated antigens (TAAs) (68). HCC expresses immune checkpoint ligands, including co-inhibitory molecules (cytotoxic $\mathrm{T}$ lymphocyte-associated antigen 4 (CTLA4), PD1, T cell immuno-globulin and mucin domain containing molecule 3 (TIM3), and lymphocyteactivation gene 3 (LAG3)) (68). Immune checkpoints expressed by effector lymphocytes subsequently bind with the ligands to inhibit overwhelming activation (68). Interaction between receptors and their ligands needs to be blocked in order to sustain the activity of effector lymphocytes against the malignant proliferation of tumor cells. Immune checkpoint inhibitors (ICIs) and monoclonal antibodies can achieve this goal. PD1 and PDL1 inhibitors have demonstrated promising results in preventing the proliferation of $\mathrm{HCC}$ cells (68).

The efficacy of atezolizumab (a PDL1 inhibitor) plus bevacizumab (a VEGF inhibitor) was confirmed by the IMbrave150 trial; the combination resulted in a PFS of 6.8 months ( $95 \%$ CI, 5.7 to 8.3 months) and an ORR of $67.2 \%$ for one year among patients with unresectable HCC (69). The combination was also recommended by 2021 NCCN guidelines as first-line therapy (category 1) for patients with Child Pugh class A liver disease. After the IMbrave 050 trial, more attention was paid to patients with a high risk of recurrence after curative resection or ablation (70). Although the combination displayed a benefit to an extent and it was superior to current systemic therapy, a subgroup analysis of a phase III study noted lower efficacy in NAFLD and HCC with activated Wnt/ $\beta$-catenin signaling (71). The incidence of NAFLD has been increasing, and NAFLD has become a main etiological risk factor for HCC in the US (71) due to imperfect screening systems, leading to advanced tumor stages. Mahipal et al. found that about $50 \%$ of HCC cases were accompanied by overactivation of the Wnt/ $\beta$-catenin signaling pathway, promoting proliferation and metastasis as well as sorafenib resistance (72-74).

The combination of GEMOX and bevacizumab resulted in an OS of 9.6 months $\mathrm{OS}(95 \% \mathrm{Cl}, 8.0$ months to not available) and a PFS of 5.3 months $(95 \% \mathrm{Cl}, 3.7$ to 8.7 months) according to a phase II study (33), but further evidence is lacking. Atezolizumab and other chemotherapy agents have displayed efficacy in triplenegative breast cancer, but there have been few studies on the combination of chemotherapeutic drugs and immune agents to treat HCC.

\section{Locoregional use of chemotherapy}

\subsection{TACE}

Although systemic chemotherapy has failed to play a major role in the treatment of HCC, local use of chemotherapeutic agents is still considerable, and approaches include TACE and HAIC. The theoretical basis for these approaches is the vascular shift where benign lesions are supplied by branches of the portal system, while malignant nodules are nourished by the hepatic artery $(3,60)$ according to CT and MRI $(3,60)$. Patients with BCLC stage B HCC are eligible for TACE (15) according to the 2021 NCCN guidelines, which specify a reasonable level of liver function (Child-Pugh class A or B) or a multinodular tumor without vascular invasion or extrahepatic metastasis $(1,4,5)$.

In addition to embolization, TACE can deliver a chemotherapeutic agent in a high concentration to a target lesion; this means less of the drug in the circulation, thus reducing adverse events $(1,4)$. TACE includes conventional TACE (cTACE) and drug-eluting bead TACE (DEB-TACE) (1,75). Doxorubicin, mitomycin C, and cisplatin are usually used in cTACE. These drugs are suspended in lipiodol for delivery to the target location, followed by embolization with gelatin sponge particles (75). DEB-TACE involves agents similar to those used in cTACE but different carriers. In DEB-TACE, beads are implanted in the tumor vasculature, where they remain for a prolonged period (75) to maximize the duration of their presence and to attenuate systemic toxicity $(4,76)$. A retrospective study initially indicated that DEB-TACE for unresectable HCC in all stages resulted in an OS of 610 days versus 284 days for cTACE (77). Moreover, a stratification analysis indicated that DEB-TACE resulted in a significant benefit for patients with Child-Pugh class A or B liver function since they potentially suffered liver failure when undergoing cTACE. Another retrospective study (78) and two prospective studies subsequently agreed with the earlier findings $(4,79)$. However, the PRECISIONV trial suggested that the two procedures have equivalent efficacy and safety, possibly due to the inclusion of patients with all BCLC stages of liver disease $(4,80)$.

Although widely used, chemoembolization remains highly controversial. A retrospective study (81) and 3 RCTs were optimistic about the benefits of TACE compared to symptomatic treatment of unresectable HCC $(82,83)$. Moreover, a subsequent meta-analysis corroborated the survival advantage of TACE (15). However, two French studies reached the opposite conclusion, possibly because of the inclusion of a disproportionate number of patients with alcoholic cirrhosis (15). In addition, an RCT over 5 years compared the efficacy of TAE and transarterial DOX 
embolization (84). The study indicated that TAE resulted in a median PFS of 6.2 months and an OS of 19.6 months versus a PFS of 2.8 months and an OS of 20.8 for the TACE arm, so the PFS and OS did not differ significantly. Does this mean that chemotherapy drugs have completely failed in both systemic and regional treatment of HCC? Fortunately, the answer is no. Despite those negative and disappointing results, the study in question did not stratify patients by BCLC stage, which led to a confounding bias. In addition, the study only used DOX and it did not consider other effective agents. Hence, a subsequent RCT compared the efficacy of cisplatin and epirubicin in TACE, and it have concluded that cisplatin was not significantly superior to epirubicin (85). Both cisplatin and mitomycin $\mathrm{C}$ have yielded consistent results according to a prospective study (86). One final aspect to consider is that the drug carrier may limit efficacy. HepaSpheres, which are vinyl alcoholsodium acryl-ate microspheres, were the conventional carrier system, and they lasted almost 30 years in clinical practice. HepaSpheres provided superior absorption and release of a chemotherapeutic drug and they were pliant in blood vessels (87). However, micron-sized iron powder, barium ferrite (BaFe12O19), and carboncoated iron nanocrystals (CCINs) are a novel carrier system (88). This new carrier enhances chemotherapy by maximizing the drug-loading capability and controlledrelease, and this new carrier system has displayed great potential in animal experiments in vitro compared to the conventional carrier system (88). Together, these aspects play an essential role in the efficacy of chemotherapeutic drugs in TACE.

\subsection{HAIC}

HAIC has been widely used in Asia, and especially in Japan $(1,89)$. HAIC's mechanism of action is to deliver a high concentration of a chemotherapeutic agent to a targeted lesion via the hepatic artery without embolization (90). There are two approaches to HAIC: single administration and continuous infusion with a subcutaneously sited reservoir system (90). Different chemotherapeutic agents involve different approaches to targeting in order for them to be most effective. In specific terms, epirubicin hydrochloride and miriplatin, which are concentration-dependent agents, can be used for bolus injection, while time-dependent agents, namely DOX and 5-FU, can be used for continuous HAIC. Notably, some agents, such as cisplatin and mitomycin $\mathrm{C}$, are suitable for both bolus injection and continuous infusion (90).

Although HAIC has been routinely used in Asia, HAIC is not mentioned as a common locoregional therapy for advanced HCC in the 2021 NCCN guidelines or by the Asian Pacific Association for the Study of the Liver (90). Therefore, attention has focused on obtaining highly reliable clinical evidence of HAIC's efficacy.
Although a systematic review and a retrospective study have indicated that HAIC conferred a survival benefit versus supportive therapy in advanced HCC (91), prolonging long-term survival was difficult due to the aggressive nature and rate of recurrence of HCC (92). Moreover, HAIC with 5-FU and cisplatin yielded a marginal survival benefit in patients with macrovascular invasion (MVI) but without extrahepatic metastasis (EHM) (93).

Would the combination of systemic therapy and HAIC result in increased efficacy? In theory, HAIC could compensate for MTAs failing to reach the expected dose at the targeted lesion because of PVTT (94), while systemic therapy could target extrahepatic lesions (52). However, the SILIUS study noted a similar OS of 11.8 months for combination therapy (HAIC (cisplatin)+ sorafenib) vs. 11.5 months for monotherapy (sorafenib) but with a higher likelihood of Grade 3-4 adverse events (95). Therefore, subsequent studies have focused on alternative agents for use in HAIC. As mentioned before, oxaliplatin is superior to cisplatin (96), so the question is whether oxaliplatin could avoid the adverse effects caused by cisplatin. A phase II and III trial on FOLFOX plus sorafenib in HAIC yielded positive results in terms of the OS (13.37 months vs. 7.13 months, $P<0.001)$, a higher RR (40.8\% vs. $2.46 \% ; P<0.001)$, and a longer PFS (7.03 [95\% CI, 6.05-8.02 months] vs. 2.6 [95\% CI, 2.15-3.05 months]; $P<0.001$ ), and especially when HAIC was combined with PVTT (96). Hence, FOLFOX has been the mainstay of HAIC $(97,98)$. Nevertheless, a cost-effectiveness analysis found that SoraHAIC was moderately cost-effective in developing areas (99). Immune therapy is recommended in the $2021 \mathrm{NCCN}$ guidelines on advanced HCC, so further studies need to be conducted to determine if HAIC is cost-effective.

Compared to TACE consistently administered via the hepatic artery, HAIC with FOLFOX resulted in a median OS (23.1 vs. 16.1 months, $P<0.001)$ and PFS (9.6 vs. 5.4 months, $P<0.001$ ) superior to those of TACE for large HCC according to a prospective non-randomized study and a randomized study $(100,101)$. However, TACE for preoperative and postoperative resection of large HCC has been studied, and its use remains controversial $(102,103)$. TACE can serve as a bridge therapy and downstaging therapy (1). That said, a point worth noting is that HAIC to treat HCC has yet to be fully examined.

\section{Discussion and Conclusion}

Conventional chemotherapy faces challenges from molecular therapy and immune therapy, but it plays an essential role in the treatment of hepatic malignancies. Over time, DOX was isolated from the pigmentproducing Streptomyces peucetius and then DOX derivatives such as PLD and LTLD were examined. The efficacy of a combination of LTLD and RFA has been confirmed in the phase III HEAT study. As 
chemotherapeutic drugs continue to advance, a variety of novel chemotherapeutic agents have been developed. in 2021, the NCCN recommended that FOLFOX serve as a first-line option (category 2B). Further advances in molecular therapy and immune therapy have challenged the dominance of conventional chemotherapy. Unlike the direct inhibition of DNA synthesis by chemotherapeutic agents, molecular strategies inhibit multi-kinases involved in cell proliferation. Molecularly targeted agents such as sorafenib and lenvatinib have demonstrated efficacy. That said, they are restricted to certain patients with Child-Pugh class A liver disease since they are not superior to conventional chemotherapy for patients with Child-Pugh class B or C liver disease. The appearance of immune agents has inaugurated a new era of systemic treatment of liver cancer, but immune therapy has a modest efficacy in circumstances involving overactivation of the $\mathrm{Wnt} / \beta$-catenin signaling pathway, which occurs in $50 \%$ of HCC and which is related to a recurrence rate as high as $70 \%$ at 5 years. Immune therapy also offers a marginal survival benefit in hepatic virus infection-related HCC. Thus, alternatives to conventional chemotherapy, MTAs, and immune therapy are particularly controversial. What strategies should be adopted for patients with Child-Pugh class B or C liver disease? What is the nature of $\mathrm{HCC}$ recurrence? The current PFS for these strategies is less than one year according to clinical studies, and the current authors have justified questions about the costs and benefits of those strategies. All of the aforementioned topics need to be examined further.

Moreover, chemotherapeutic agents have been used to treat locoregional lesions through approaches such as TACE and HAIC. TACE includes cTACE and DEBTACE. Various agents are used in TACE systems. In addition, HAIC is a consistent transcatheter arterial infusion strategy without embolization that is often used because it delivers a drug at a higher concentration. FOLFOX is a mainstay of HAIC. Moreover, HAIC is superior to TACE according to a recent prospective study. Although HAIC confers overwhelming advantages and is likely to have the most potential as a therapy, it is only used in Asia and is not mentioned in guidelines globally. Moreover, TACE can serve as a bridge therapy and downstaging therapy; whether HAIC can perform those roles is uncharted territory.

Funding: This work was supported by grants from the National Key Technologies R\&D Program (2018YFC1106800), the Natural Science Foundation of China $(82173124,82173248,82103533,82002572$, 82002967,81972747 , and 81872004), the National Program to Support Innovative Postdoctoral Personnel (BX20200225, BX20200227), China's Postdoctoral Science Foundation (2021M692278, 2020M673231), Sichuan Province's Program to Support Science and Technology (2021YJ0436), the Postdoctoral Science
Foundation of Sichuan University (2021SCU12007), the 1.3.5 Project for Fields of Excellence, Sichuan University's West China Hospital (ZYJC18008), and West China Hospital's Postdoctoral Science Foundation (2020HXBH075, 2020HXBH007).

Conflict of Interest: The authors have no conflicts of interest to disclose.

\section{References}

1. Benson AB, D'Angelica MI, Abbott DE, et al. Hepatobiliary Cancers, Version 2.2021, NCCN Clinical Practice Guidelines in Oncology. J Natl Compr Canc Netw. 2021; 19:541-565.

2. Bugter JM, Fenderico N, Maurice MM. Mutations and mechanisms of WNT pathway tumour suppressors in cancer. Nat Rev Cancer. 2021; 21:5-21.

3. Villanueva A. Hepatocellular Carcinoma. N Engl J Med. 2019; 380:1450-1462.

4. Lammer J, Malagari K, Vogl T, et al. Prospective randomized study of doxorubicin-eluting-bead embolization in the treatment of hepatocellular carcinoma: Results of the PRECISION V study. Cardiovasc Intervent Radiol. 2009; 33:41-52.

5. Llovet JM, Kelley RK, Villanueva A, Singal AG, Pikarsky E, Roayaie S, Lencioni R, Koike K, Zucman-Rossi J, Finn RS. Hepatocellular carcinoma. Nat Rev Dis Primers. 2021; 7:6.

6. Dienstag JL. Hepatitis B virus infection. N Engl J Med. 2008, 359:1486-500.

7. Levrero M, Zucman-Rossi J. Mechanisms of HBVinduced hepatocellular carcinoma. J Hepatol. 2016; 64:S84-S101.

8. Estes C, Anstee QM, Arias-Loste MT, et al. Modeling NAFLD disease burden in China, France, Germany, Italy, Japan, Spain, United Kingdom, and United States for the period 2016-2030. J Hepatol. 2018; 69:896-904.

9. Yau T, Tang VY, Yao TJ, Fan ST, Lo CM, Poon RT. Development of Hong Kong Liver Cancer staging system with treatment stratification for patients with hepatocellular carcinoma. Gastroenterology. 2014; 146:1691-1700 e1693.

10. Gallo C. A new prognostic system for hepatocellular carcinoma: A retrospective study of 435 patients: The Cancer of the Liver Italian Program (CLIP) investigators. Hepatology. 1998; 28:751-755.

11. Llovet JM, Bru C, Bruix J. Prognosis of hepatocellular carcinoma: The BCLC staging classification. Semin Liver Dis. 1999; 19:329-338.

12. Bruix J, Llovet JM. Prognostic prediction and treatment strategy in hepatocellular carcinoma. Hepatology. 2002; 35:519-524.

13. Llovet J M, Fuster J, Bruix J. Intention-to-treat analysis of surgical treatment for early hepatocellular carcinoma: Resection versus transplantation. Hepatology. 1999; 30:1434-440.

14. Sugawara Y, Hibi T. Surgical treatment of hepatocellular carcinoma. BioSci Trends. 2021; 15:138-141.

15. O'Neil BH, Venook AP. Hepatocellular carcinoma: The role of the North American GI Steering Committee Hepatobiliary Task Force and the advent of effective drug therapy. Oncologist. 2007; 12:1425-1432. 
16. Gish RG, Porta C, Lazar L, Ruff P, Feld R, Croitoru A, Feun L, Jeziorski K, Leighton J, Gallo J, Kennealey GT. Phase III randomized controlled trial comparing the survival of patients with unresectable hepatocellular carcinoma treated with nolatrexed or doxorubicin. J Clin Oncol. 2007; 25:3069-3075.

17. Minotti G, Menna P, Salvatorelli E, Cairo G, Gianni L. Anthracyclines: Molecular advances and pharmacologic developments in antitumor activity and cardiotoxicity. Pharmacol Rev. 2004; 56:185-229.

18. Takemura G, Fujiwara H. Doxorubicin-induced cardiomyopathy from the cardiotoxic mechanisms to management. Prog Cardiovasc Dis. 2007; 49:330-352.

19. Nerenstone SR, Ihde DC, Friedman MA. Clinical trials in primary hepatocellular carcinoma: Current status and future directions. Cancer Treat Rev. 1988; 15:1-31.

20. Valle JW, Dangoor A, Beech J, Sherlock DJ, Lee SM, Scarffe JH, Swindell R, Ranson M. Treatment of inoperable hepatocellular carcinoma with pegylated liposomal doxorubicin (PLD): Results of a phase II study. Br J Cancer. 2005; 92:628-630.

21. Lind PA, Naucler G, Holm A, Gubanski M, Svensson C. Efficacy of pegylated liposomal doxorubicin in patients with advanced hepatocellular carcinoma. Acta Oncol. 2007; 46:230-233.

22. Hong RL, Tseng YL. A phase II and pharmacokinetic study of pegylated liposomal doxorubicin in patients with advanced hepatocellular carcinoma. Cancer Chemother Pharmacol. 2003; 51:433-438.

23. Tak WY, Lin SM, Wang Y, et al. Phase III HEAT study adding lyso-thermosensitive liposomal doxorubicin to radiofrequency ablation in patients with unresectable hepatocellular carcinoma lesions. Clin Cancer Res. 2018; 24:73-83.

24. Poon RTP, Borys N. Lyso-thermosensitive liposomal doxorubicin: An adjuvant to increase the cure rate of radiofrequency ablation in liver cancer. Future Oncol. 2011; 7:937-945.

25. Zamboni WC. Concept and clinical evaluation of carriermediated anticancer agents. Oncologist. 2008; 13:248260.

26. Kong G, Anyarambhatla G, Petros WP, Braun RD, Colvin OM, Needham D, Dewhirst MW. Efficacy of liposomes and hyperthermia in a human tumor xenograft model: Importance of triggered drug release. Cancer Res. 2000; 60:6950-6957.

27. Gao J, Wang J, Jin Y, Zhang F, Yang X. Intratumoral radiofrequency hyperthermia-enhanced chemotherapy of liposomal doxorubicin on hepatocellular carcinoma. Am J Transl Res. 2018; 10:3619-3627.

28. Celik H, Wakim P, Pritchard WF, Castro M, Leonard S, Karanian JW, Dewhirst MW, Lencioni R, Wood BJ. Radiofrequency ablation duration per tumor volume may correlate with overall survival in solitary hepatocellular carcinoma patients treated with radiofrequency ablation plus lyso-thermosensitive liposomal doxorubicin. J Vasc Interv Radiol. 2019; 30:1908-1914.

29. Lee JO, Lee KW, Oh DY, Kim JH, Im SA, Kim TY, Bang YJ. Combination chemotherapy with capecitabine and cisplatin for patients with metastatic hepatocellular carcinoma. Ann Oncol. 2009; 20:1402-1407.

30. Ikeda M, Okusaka T, Ueno H, Takezako Y, Morizane C. A phase II trial of continuous infusion of 5-fluorouracil, mitoxantrone, and cisplatin for metastatic hepatocellular carcinoma. Cancer. 2005; 103:756-762.
31. Yeo W, Mok TS, Zee B, et al. A randomized phase III study of doxorubicin versus cisplatin/interferon $\alpha-2 b /$ doxorubicin/fluorouracil (PIAF) combination chemotherapy for unresectable hepatocellular carcinoma. JNCI: J Natl Cancer Inst. 2005; 97:1532-1538.

32. Azim HA, Omar A, Atef H, Zawahry H, Shaker MK, Abdelmaksoud AK, EzzElarab M, Abdel-Rahman O, Ismail M, Kassem L, Waked I. Sorafenib plus tegafururacil (UFT) versus sorafenib as first line systemic treatment for patients with advanced stage HCC: A Phase II trial (ESLC01 study). J Hepatocell Carcinoma. 2018; 5:109-119.

33. Zhu AX, Blaszkowsky LS, Ryan DP, Clark JW, Muzikansky A, Horgan K, Sheehan S, Hale KE, Enzinger PC, Bhargava P, Stuart K. Phase II study of gemcitabine and oxaliplatin in combination with bevacizumab in patients with advanced hepatocellular carcinoma. J Clin Oncol. 2006; 24:1898-903.

34. Lee S, Yoon SH, Park JY, Kim DY, Ahn SH, Han KH, Choi HJ. Sorafenib versus cytotoxic chemotherapy for patients with advanced hepatocellular carcinoma: A retrospective, single-institution study. Invest New Drugs. 2012; 30:1150-1157.

35. Lombardi G, Zustovich F, Farinati F, Cillo U, Vitale A, Zanus G, Donach M, Farina M, Zovato S, Pastorelli D. Pegylated liposomal doxorubicin and gemcitabine in patients with advanced hepatocellular carcinoma: Results of a phase 2 study. Cancer. 2011; 117:125-133.

36. Richter SN, Cartei G, Nadai M, Trestin A, Barzon L, Palumbo M, Palu G. In vitro basis for schedule-dependent interaction between gemcitabine and topoisomerasetargeted drugs in the treatment of colorectal cancer. Ann Oncol. 2006; 17 Suppl 5:v20-24.

37. Miwa M, Ura M., Nishida M, Sawada N, Ishikawa T, Mori K, Shimma N, Umeda I, Ishitsuka H. Design of a novel oral fluoropyrimidine carbamate, capecitabine, which generates 5-fluorouracil selectively in tumours by enzymes concentrated in human liver and cancer tissue. Eur J Cancer. 1998; 34:1274-81.

38. Patt YZ, Hassan MM, Aguayo A, Nooka AK, Lozano RD, Curley SA, Vauthey JN, Ellis LM, Schnirer, II, Wolff RA, Charnsangavej C, Brown TD. Oral capecitabine for the treatment of hepatocellular carcinoma, cholangiocarcinoma, and gallbladder carcinoma. Cancer. 2004; 101:578-586.

39. Kelland L. The resurgence of platinum-based cancer chemotherapy. Nat Rev Cancer. 2007; 7:573-584.

40. Imogen A Riddell, Stephen J. Lippard. Cisplatin and oxaliplatin: Our current understanding of their actions. Met Ions Life Sci. 2018;18. doi: 10.1515/9783110470734007.

41. Kidani Y, Inagaki K, Iigo M, Hoshi A, Kuretani K. Antitumor activity of 1,2-diaminocyclohexane-platinum complexes against sarcoma-180 ascites form. J Med Chem. 1978; 21:1315-1318.

42. Lévi F, Misset J L, Brienza S, Adam R, Metzger G, Itzakhi M, Caussanel J, Kunstlinger F, Lecouturier S, DescorpsDeclère A. A chronopharmacologic phase II clinical trial with 5-fluorouracil, folinic acid, and oxaliplatin using an ambulatory multichannel programmable pump. High antitumor effectiveness against metastatic colorectal cancer. Cancer. 1992; 69:893-900.

43. Abdolvahab MH, Darvishi B, Zarei M, Majidzadeh-A $\mathrm{K}$, Farahmand L. Interferons: Role in cancer therapy. Immunotherapy. 2020;12:833-855. 
44. Rizell M, Cahlin C, Friman S, Hafstrom L, Lonn L, Olausson M, Lindner P. Impressive regression of primary liver cancer after treatment with sirolimus. Acta Oncol. 2005; 44:496.

45. Yang TS, Lin YC, Chen JS, Wang HM, Wang CH. Phase II study of gemcitabine in patients with advanced hepatocellular carcinoma. Cancer. 2000; 89:750-756.

46. Cartei G, Trestin A, Colombrino E, Nadai M, Richter SN, Barzon L, Palu G, Palumbo M, Padua Pharmacology Oncology G. Topoisomerase I, II alpha and II beta mRNA expression in peripheral blood mononuclear cells of patients with solid tumor: Preliminary results. Ann Oncol. 2006; 17 Suppl 5:v25-28.

47. Louafi S, Boige V, Ducreux M, Bonyhay L, Mansourbakht T, de Baere T, Asnacios A, Hannoun L, Poynard T, Taieb J. Gemcitabine plus oxaliplatin (GEMOX) in patients with advanced hepatocellular carcinoma (HCC): Results of a phase II study. Cancer. 2007; 109:1384-1390.

48. Glimelius B, Stintzing S, Marshall J, Yoshino T, de Gramont A. Metastatic colorectal cancer: Advances in the folate-fluoropyrimidine chemotherapy backbone. Cancer Treat Rev. 2021; 98:102218.

49. Qin S, Bai Y, Lim HY, Thongprasert S, Chao Y, Fan J, Yang TS, Bhudhisawasdi V, Kang WK, Zhou Y, Lee JH, Sun Y. Randomized, multicenter, open-label study of oxaliplatin plus fluorouracil/leucovorin versus doxorubicin as palliative chemotherapy in patients with advanced hepatocellular carcinoma from Asia. J Clin Oncol. 2013; 31:3501-3588

50. Azmy AM, Nasr KE, Gobran NS, Yassin M. Gemcitabine plus carboplatin in patients with advanced hepatocellular carcinoma: Results of a phase II study. ISRN Oncol. 2012; 2012:420931.

51. Pastorelli D, Cartei G, Zustovich F, Marchese F, Artioli G, Zovato S, Binato S, Ceravolo R, Cingarlini S, Salmaso F, Mattiazzi M, Sanavio C, Farinati F, Zanus G, Cillo U. Gemcitabine and liposomal doxorubicin in biliary and hepatic carcinoma (HCC) chemotherapy: Preliminary results and review of the literature. Ann Oncol. 2006; 17 Suppl 5:v153-157.

52. Kosaka Y, Kimura T, Kawaoka T, et al. Hepatic arterial infusion chemotherapy combined with radiation therapy for advanced hepatocellular carcinoma with tumor thrombosis of the main trunk or bilobar of the portal vein. Liver Cancer. 2021; 10:151-160.

53. Llovet JM, Ricci S, Mazzaferro V, et al. Sorafenib in advanced hepatocellular carcinoma. N Engl J Med. 2008; 359:378-390.

54. Chang YS, Adnane J, Trail PA, et al. Sorafenib (BAY 43-9006) inhibits tumor growth and vascularization and induces tumor apoptosis and hypoxia in RCC xenograft models. Cancer Chemother Pharmacol. 2007; 59:561-574.

55. Faivre S, Rimassa L, Finn RS. Molecular therapies for HCC: Looking outside the box. J Hepatol. 2020; 72:342352.

56. Zhu AX, Rosmorduc O, Evans TR, Ross PJ, Santoro A, Carrilho FJ, Bruix J, Qin S, Thuluvath PJ, Llovet JM, Leberre MA, Jensen M, Meinhardt G, Kang YK. SEARCH: A phase III, randomized, double-blind, placebo-controlled trial of sorafenib plus erlotinib in patients with advanced hepatocellular carcinoma. J Clin Oncol. 2015; 33:559-566.

57. Johnson PJ, Qin S, Park JW, et al. Brivanib versus sorafenib as first-line therapy in patients with unresectable, advanced hepatocellular carcinoma: Results from the randomized phase III BRISK-FL study. J Clin Oncol. 2013; 31:3517-3524.

58. Cheng AL, Kang YK, Lin DY, et al. Sunitinib versus sorafenib in advanced hepatocellular cancer: results of a randomized phase III trial. J Clin Oncol. 2013; 31:40674075.

59. Cainap C, Qin S, Huang WT, et al. Linifanib versus sorafenib in patients with advanced hepatocellular carcinoma: Results of a randomized phase III trial. J Clin Oncol. 2015; 33:172-179.

60. Zhu AX, Kudo M, Assenat E, et al. Effect of everolimus on survival in advanced hepatocellular carcinoma after failure of sorafenib: The EVOLVE-1 randomized clinical trial. JAMA. 2014; 312:57-67.

61. Kudo M, Finn RS, Qin S, et al. Lenvatinib versus sorafenib in first-line treatment of patients with unresectable hepatocellular carcinoma: A randomised phase 3 non-inferiority trial. Lancet. 2018; 391:1163-1173.

62. Kim JJ, McFarlane T, Tully S, Wong WWL. Lenvatinib versus sorafenib as first-line treatment of unresectable hepatocellular carcinoma: A cost-utility analysis. Oncologist. 2020; 25:e512-e519.

63. Bruix J, Qin S, Merle P, et al. Regorafenib for patients with hepatocellular carcinoma who progressed on sorafenib treatment (RESORCE): A randomised, doubleblind, placebo-controlled, phase 3 trial. Lancet. 2017; 389:56-66.

64. Cheng AL, Kang YK, Chen Z, et al. Efficacy and safety of sorafenib in patients in the Asia-Pacific region with advanced hepatocellular carcinoma: A phase III randomised, double-blind, placebo-controlled trial. Lancet Oncol. 2009; 10:25-34.

65. Hsu C, Shen YC, Cheng CC, Hu FC, Cheng AL. Geographic difference in survival outcome for advanced hepatocellular carcinoma: Implications on future clinical trial design. Contemp Clin Trials. 2010; 31:55-61.

66. Assenat E, Pageaux GP, Thezenas S, Peron JM, Becouarn Y, Seitz JF, Merle P, Blanc JF, Bouche O, Ramdani M, Poujol S, de Forges H, Ychou M, Boige V. Sorafenib alone $v s$. sorafenib plus GEMOX as 1(st)-line treatment for advanced HCC: The phase II randomised PRODIGE 10 trial. Br J Cancer. 2019; 120:896-902.

67. Liu Y, Yue H, Xu S, Wang F, Ma N, Li K, Qiao L, Wang J. First-line gemcitabine and oxaliplatin (GEMOX) plus sorafenib, followed by sorafenib as maintenance therapy, for patients with advanced hepatocellular carcinoma: A preliminary study. Int J Clin Oncol. 2015; 20:952-959.

68. Sangro B, Sarobe P, Hervas-Stubbs S, Melero I. Advances in immunotherapy for hepatocellular carcinoma. Nat Rev Gastroenterol Hepatol. 2021; 18:525-543.

69. Finn RS, Qin S, Ikeda M, et al. Atezolizumab plus bevacizumab in unresectable hepatocellular carcinoma. N Engl J Med. 2020; 382:1894-1905.

70. Hack SP, Spahn J, Chen M, Cheng AL, Kaseb A, Kudo M, Lee HC, Yopp A, Chow P, Qin S. IMbrave 050: A Phase III trial of atezolizumab plus bevacizumab in highrisk hepatocellular carcinoma after curative resection or ablation. Future Oncol. 2020; 16:975-989.

71. Pinter M, Scheiner B, Peck-Radosavljevic M. Immunotherapy for advanced hepatocellular carcinoma: A focus on special subgroups. Gut. 2021; 70:204-214.

72. Llovet JM, Bruix J. Molecular targeted therapies in hepatocellular carcinoma. Hepatology. 2008; 48:1312-27

73. Guo F, Wang H, Jiang M, Yang Q, Xiang Q, Zhou H, Hu X, Hao K, Yang J, Cao H, Shen Z. TDP-43 induces EMT 
and promotes hepatocellular carcinoma metastasis via activating Wnt/ $\beta$-catenin signaling pathway. Am J Cancer Res. 2020; 10:3285-3301.

74. Shibata T, Arai Y, Totoki Y. Molecular genomic landscapes of hepatobiliary cancer. Cancer Sci. 2018; 109:1282-1291.

75. Galle PR, Tovoli F, Foerster F, Worns MA, Cucchetti A, Bolondi L. The treatment of intermediate stage tumours beyond TACE: From surgery to systemic therapy. J Hepatol. 2017; 67:173-183.

76. Morishita A, Tani J, Nomura T, et al. Efficacy of combined therapy with drug-eluting beads-transcatheter arterial chemoembolization followed by conventional transcatheter arterial chemoembolization for unresectable hepatocellular carcinoma: A multi-center study. Cancers (Basel). 2021; 13:4605.

77. Dhanasekaran R, Kooby DA, Staley CA, Kauh JS, Khanna V, Kim HS. Comparison of conventional transarterial chemoembolization (TACE) and chemoembolization with doxorubicin drug eluting beads (DEB) for unresectable hepatocellular carcinoma (HCC). J Surg Oncol. 2010; 101:476-480.

78. Song MJ, Chun HJ, Song DS, Kim HY, Yoo SH, Park CH, Bae SH, Choi JY, Chang UI, Yang JM, Lee HG, Yoon SK. Comparative study between doxorubicin-eluting beads and conventional transarterial chemoembolization for treatment of hepatocellular carcinoma. J Hepatol. 2012; 57:1244-1250.

79. Malagari K, Pomoni M, Kelekis A, Pomoni A, Dourakis S, Spyridopoulos T, Moschouris H, Emmanouil E, Rizos $\mathrm{S}$, Kelekis D. Prospective randomized comparison of chemoembolization with doxorubicin-eluting beads and bland embolization with BeadBlock for hepatocellular carcinoma. Cardiovasc Intervent Radiol. 2010; 33:541551.

80. Golfieri R, Giampalma E, Renzulli M, Cioni R, Bargellini I, Bartolozzi C, Breatta AD, Gandini G, Nani R, Gasparini D, Cucchetti A, Bolondi L, Trevisani F, Precision Italia Study G. Randomised controlled trial of doxorubicineluting beads $v s$ conventional chemoembolisation for hepatocellular carcinoma. Br J Cancer. 2014; 111:255264.

81. Kong JY, Li SM, Fan HY, Zhang L, Zhao HJ, Li SM. Transarterial chemoembolization extends long-term survival in patients with unresectable hepatocellular carcinoma. Medicine (Baltimore). 2018; 97:e11872.

82. Lo CM, Ngan H, Tso WK, Liu CL, Lam CM, Poon RT, Fan ST, Wong J. Randomized controlled trial of transarterial lipiodol chemoembolization for unresectable hepatocellular carcinoma. Hepatology. 2002; 35:11641171.

83. Llovet JM, Real MI, Montaña X, Planas R, Coll S, Aponte J, Ayuso C, Sala M, Muchart J, Solà R, Rodés J, Bruix J. Arterial embolisation or chemoembolisation versus symptomatic treatment in patients with unresectable hepatocellular carcinoma: A randomised controlled trial. Lancet. 2002; 359:1734-1739.

84. Brown KT, Do RK, Gonen M, et al. Randomized trial of hepatic artery embolization for hepatocellular carcinoma using doxorubicin-eluting microspheres compared with embolization with microspheres alone. J Clin Oncol. 2016; 34:2046-2053.

85. Aramaki O, Takayama T, Moriguchi M, et al. Arterial chemoembolisation with cisplatin versus epirubicin for hepatocellular carcinoma (ACE 500 study): A multicentre, randomised controlled phase 2/3 trial. Eur J Cancer. 2021;
157:373-382.

86. Sahara S, Kawai N, Sato M, Tanaka T, Ikoma A, Nakata K, Sanda H, Minamiguchi H, Nakai M, Shirai S, Sonomura T. Prospective evaluation of transcatheter arterial chemoembolization (TACE) with multiple anti-cancer drugs (epirubicin, cisplatin, mitomycin c, 5-fluorouracil) compared with TACE with epirubicin for treatment of hepatocellular carcinoma. Cardiovasc Intervent Radiol. 2012; 35:1363-1371.

87. Zhao G, Liu S, Chen S, Ren Z, Li C, Bian J, Wu J, Zhou J, Zhang Y. Assessment of efficacy and safety by CalliSpheres versus HepaSpheres for drug-eluting bead transarterial chemoembolization in unresectable large hepatocellular carcinoma patients. Drug Deliv. 2021; 28:1356-1362

88. Zhao P, Zhao J, Deng Y, Zeng G, Jiang Y, Liao L, Zhang S, Tao Q, Liu Z, Tang X, Tu X, Jiang L, Zhang H, Zheng Y. Application of iron/barium ferrite/carbon-coated iron nanocrystal composites in transcatheter arterial chemoembolization of hepatocellular carcinoma. J Colloid Interface Sci. 2021; 601:30-41.

89. Llovet JM, De Baere T, Kulik L, Haber PK, Greten TF, Meyer T, Lencioni R. Locoregional therapies in the era of molecular and immune treatments for hepatocellular carcinoma. Nat Rev Gastroenterol Hepatol. 2021; 18:293313.

90. Obi S, Sato S, Kawai T. Current status of hepatic arterial infusion chemotherapy. Liver Cancer. 2015; 4:188-199.

91. Long GB, Xiao CW, Zhao XY, Zhang J, Li X. Effects of hepatic arterial infusion chemotherapy in the treatment of hepatocellular carcinoma: A meta-analysis. Medicine (Baltimore). 2020; 99:e20745.

92. Nouso K, Miyahara K, Uchida D, et al. Effect of hepatic arterial infusion chemotherapy of 5-fluorouracil and cisplatin for advanced hepatocellular carcinoma in the Nationwide Survey of Primary Liver Cancer in Japan. Br J Cancer. 2013 1; 109:1904-1907.

93. Ueshima K, Ogasawara S, Ikeda M, et al. Hepatic arterial infusion chemotherapy versus sorafenib in patients with advanced hepatocellular carcinoma. Liver Cancer. 2020; 9:583-595.

94. Qiu G, Xie K, Jin Z, Jiang C, Liu H, Wan H, Huang J. The multidisciplinary management of hepatocellular carcinoma with portal vein tumor thrombus. BioSci Trends. 2021; 15:148-154.

95. Kudo M, Ueshima K, Yokosuka O, et al. Sorafenib plus low-dose cisplatin and fluorouracil hepatic arterial infusion chemotherapy versus sorafenib alone in patients with advanced hepatocellular carcinoma (SILIUS): A randomised, open label, phase 3 trial. Lancet Gastroenterol Hepatol. 2018; 3:424-432.

96. He M, Li Q, Zou R, et al. Sorafenib plus hepatic arterial infusion of oxaliplatin, fluorouracil, and leucovorin vs sorafenib alone for hepatocellular carcinoma with portal vein invasion: A randomized clinical trial. JAMA Oncol. 2019; 5:953-960.

97. Li S, Mei J, Wang Q, Guo Z, Lu L, Ling Y, Xu L, Chen M, Zheng L, Lin W, Zou J, Wen Y, Wei W, Guo R. Postoperative adjuvant transarterial infusion chemotherapy with FOLFOX could improve outcomes of hepatocellular carcinoma patients with microvascular invasion: A preliminary report of a phase III, randomized controlled clinical trial. Ann Surg Oncol. 2020; 27:5183-5190.

98. Mei J, Tang YH, Wei W, Shi M, Zheng L, Li SH, Guo RP. Hepatic arterial infusion chemotherapy combined with 
PD-1 inhibitors plus lenvatinib versus PD-1 inhibitors plus lenvatinib for advanced hepatocellular carcinoma. Front Oncol. 2021; 11:618206.

99. Li M, Lin S, Wilson L, Huang P, Wang H, Lai S, Dong $\mathrm{L}, \mathrm{Xu}$ X, Weng X. Cost-effectiveness analysis of hepatic arterial infusion of FOLFOX combined sorafenib for advanced hepatocellular carcinoma with portal vein invasion. Front Oncol. 2021; 11:562135.

100. Li QJ, He MK, Chen HW, Fang WQ, Zhou YM, Xu L, Wei W, Zhang YJ, Guo Y, Guo RP, Chen MS, Shi M. Hepatic arterial infusion of oxaliplatin, fluorouracil, and leucovorin versus transarterial chemoembolization for large hepatocellular carcinoma: A randomized phase III trial. J Clin Oncol. 2022; 40:150-160.

101. He MK, Le Y, Li QJ, Yu ZS, Li SH, Wei W, Guo RP, Shi M. Hepatic artery infusion chemotherapy using mFOLFOX versus transarterial chemoembolization for massive unresectable hepatocellular carcinoma: A prospective nonrandomized study. Chin J Cancer. 2017; 36:83.

102. Li C, Wang MD, Lu L, et al. Preoperative transcatheter arterial chemoembolization for surgical resection of huge hepatocellular carcinoma $(\geq 10 \mathrm{~cm})$ : A multicenter propensity matching analysis. Hepatol Int. 2019; 13:736747.

103. El-Gendi A, El-Shafei M, Bedewy E. Combined liver resection and transarterial chemoembolization versus liver resection alone for the management of solitary large exophytic hepatocellular carcinoma with extrahepatic arterial supply: Is two always better than one? The Egyptian Journal of Surgery. 2018; 37:78-88.

Received January 12, 2022; Revised February 8, 2022; Accepted February 12, 2022.

${ }^{\S}$ These authors contributed equally to this work.

*Address correspondence to:

Jiwei Huang, Department of Liver Surgery and Liver Transplantation Center, West China Hospital, Sichuan University, No. 37 GuoXueXiang Road, Wuhou District, Chengdu 610041, China.

E-mail: huangjiweimd@hotmail.com

Released online in J-STAGE as advance publication February 15, 2022. 